\title{
Analysis of concentration degree and concentration period of short-time heavy precipitation and difference analysis based on Morlet wavelet analysis
}

\author{
Rong Sun*
}

\author{
Nantong Haimen District Meteorological Bureau \\ Nantong, JiangSu, China \\ sunjiasi3@126.com
}

\begin{abstract}
As the extreme weather led by short-time heavy precipitation has brought more and more obvious impact on urban social stability and residents' life in recent years, studying the occurrence and development of short-time heavy precipitation has become an indispensable puzzle to fill the blank of urban planning decision-making. Based on the analysis of the correlation between short-term heavy precipitation and annual precipitation in the Nantong area, this paper analyzes the annual precipitation concentration degree and the distribution of concentration period by using hourly, daily and yearly precipitation observation data from 1980 to 2020 . The results show that the spatial distribution of overall precipitation levels in Nantong is not uniform. There are more annual precipitation levels in the central inland area of Nantong than in the other stations. The meteorological disaster levels of short-term heavy precipitation are higher than in the other stations. The urban management difficulty of flood control and flood control and the optimization of urban pipe networks are more urgent than the other stations. The average annual precipitation of Nantong stations show the phenomenon of alternating for 8 years period, the plum rain period precipitation stations significantly more or fewer years to annual precipitation was also significantly more or less, and the plum rains period precipitation years significantly more generally in the rainfall harvest period, significantly fewer years generally located in the precipitation, water. The short-time heavy precipitation at all stations in Nantong mostly occurs in flood season (May-September). The diurnal variation conforms to the characteristics of double peak values in the Yangtze River and Huaihe River basin. The frequency of short-time heavy precipitation in Nantong urban areas is the most frequent. The increase of short-time heavy precipitation and precipitation will affect the increase of precipitation in the plum rain season and annual precipitation.
\end{abstract}

Keyword-Morlet wavelet analysis, short-time heavy precipitation, Precipitation concentration, Precipitation concentration period

\section{INTRODUCTION}

Extreme weather and climate events increased after 2000 [ 1 ]. Some scientists believe that geomorphic changes caused by the excessive economic development of human beings are one of the main reasons for extreme events. Nantong city is close to the river and the sea, with a developed economy and a humid monsoon climate in the northern subtropics. In 2020, Nantong experienced the longest plum rain ever recorded, and the water level of the Yangtze River exceeded the historical extreme value. Compared with the first decade of this century, the annual average number of rainstorm days in Nantong increased by 2.3 times. The annual average number of hightemperature days increased by 1.6 times in recent five years. Annual precipitation, daily rainfall, hourly rainfall, high-temperature days, and extreme high and lowtemperature values in many places were continuously broken. The frequent occurrence of extreme weather and climate events, such as typhoons, thunderstorms, heavy rains, high temperatures, local tornadoes and thunderstorms, poses great risks to the safety of people's lives and property and economic and social development. Among them, short-time heavy rainfall, due to its sudden occurrence, short duration and high intensity, is easy to cause mountain flood, debris flow, urban waterlogging and other disasters, posing a great threat to people's lives and property, and causing huge damage to infrastructure, nature and our environment [2]. Such extreme events are relatively rare. When they occur, they usually greatly affect economic development and the sustainability of 
living conditions and put forward high requirements for the risk management and control ability of the government's disaster prevention and mitigation system. On the other hand, the uneven distribution of precipitation within a year is also an important influencing factor for the occurrence of natural disasters such as landslides and debris flows [3]. Moreover, due to the uneven distribution of precipitation within a year, drought and flood disasters are frequent, causing serious economic losses and casualties every year [4]. Therefore, it is of great theoretical and practical significance to study the nonuniform distribution of precipitation, especially shorttime heavy precipitation.

Many scholars have analyzed the characteristics of short-time heavy rainfall. In recent years, the frequency of short-time heavy rainfall in many countries and regions has shown an increasing trend. Konstantia's study pointed out that the increase of overall precipitation concentration in Greece was attributed to the decrease of annual warm rain circulation frequency [ 5 ]. The precipitation concentration index is used to measure the temporal variation of daily precipitation within a year, correctly reflecting the attributes of precipitation concentration in a certain period. From the precipitation concentration index perspective, China has the highest precipitation concentration, with $25 \%$ of the maximum precipitation days concentrating $90.5 \%$ of the rainfall [6]. Precipitation concentration in China is not only high but also varies greatly among different regions. Zhao Dongsheng et al. [7] found that precipitation increased in the northwest and southeast China nationwide while decreasing in the area near the ecological transition zone from northeast to southwest. Precipitation concentration in other ecological zones decreased significantly except for humid subtropical and humid tropical regions. Yang Suying et al. [8] found that extreme precipitation in Northeast China gradually decreased from south to north, and the more extreme precipitation in flood season, the more concentrated extreme precipitation. Yang Wei et al. [9] studied precipitation concentration degree and concentration period over the Plateau. They discussed and found that precipitation concentration degree was significantly positively correlated with the number of heavy precipitation days and heavy precipitation over the Plateau. Qin Weijian et al. [10] found that the stable situation of subtropical high in the east and low in the west in summer and autumn was conducive to the high concentration of rainstorms in Guangxi. Yuan Ruiqiang et al. [11] found that during the cold phase of Pacific Interdecadal Oscillation (PDO), the western Pacific subtropical high moved westward and became stronger. The annual precipitation concentration index $(\mathrm{CI})$ value in Shanxi was high, which increased the possibility of extremely heavy precipitation. According to the analysis of MAO Dongyan et al. [ 12 ], short-term heavy precipitation in Southwest China mainly concentrated from April to November, with obvious night occurrence, and showed a trend of increasing frequency and intensity trend in the recent 30 years.

There are also many factors influencing short-time heavy precipitation. Boers, N. et al. [13] found that tropical disturbance significantly influenced short-time heavy precipitation events in mid-latitude. Richard P. Allan et al. [14] found that the summer heavy rainfall events in The UK were related to the potential abnormal height, and the relatively dry anticyclonic conditions may be the necessary conditions to produce the most extreme short-time heavy rainfall. Tsubasa et al. [15] found that short-term heavy rainfall in Japan has an obvious trend of increase, so they proposed the use of peak reduction storage infrastructure in the branch drainage area and short-term heavy rainfall area and the use of rainwater storage facilities to upgrade the main drainage system in the future. Ceresetti et al. [16] analyzed the probability distribution of heavy precipitation in the Mediterranean Region. They found that there was more rainfall distribution in the flat area between the coast and the foothills. Chen Jiong et al. [17] found that the region with the highest frequency of short-time heavy precipitation in China was south China, and its diurnal variation characteristics were consistent with those of the mesoscale convective system. Still, there was a great difference between them after midnight. Huang Jie et al. [18] analyzed the characteristics and attribution of precipitation change in the first flood season in southeast China. They found that the contribution of human activities to extreme precipitation in the stage of rapid social and economic development was significantly greater than that in the stage of slow development.

All research above respectively in different fields of precipitation concentration degree and concentration period change and analyze the short-time strong rainfall, but China is a large country, north and south big differences, together with the government in the rainwater management policy of "one policy for one city" [19], requires cities researchers must identify rainfall characteristics to analyze the differences of this area. There are relatively few studies on the precipitation concentration degree and concentration period of shorttime heavy rainfall in Nantong. Therefore, this paper will discuss this to improve the urban and local meteorological flood control standards in Nantong and guarantee the construction of sponge city, resilient city, ecological city and climate-resilient city.

The main research contents include the following aspects: (1) considering the non-uniformity of precipitation distribution in a year, the characteristic values of precipitation in the Nantong region under different precipitation frequencies are determined, and its spatial distribution is discussed. (2) To analyze the tenday and diurnal variations of short-time heavy rainfall at each station in the Nantong area. (3) Discuss the concentration degree of short-time heavy rainfall and the 
concentration period distribution in the year.

\section{Materials ANd Methods}

\subsection{Study area and data collection classification}

The data used are hourly, daily, and monthly precipitation data of 8 stations in the Nantong area, with a period from 1980 to 2020, in which the period of annual precipitation data is from 1960 to 2020 . Short-time heavy precipitation standard is defined as rainfall of more than or equal to $20 \mathrm{~mm}$ in one hour [20]. Therefore, hourly rainfall will be screened according to this standard in this paper.

\subsection{Index basis of research data}

\subsubsection{Precipitation frequency}

The characteristic values of precipitation in Nantong under different precipitation frequencies were determined, and the representative years of abundant, flat and dry water years were given. The calculation formula of precipitation frequency $(\mathrm{P})$ is as follows:

$$
P=\frac{m}{n+1}
$$

$\mathrm{m}$ is the serial number of precipitation in descending order, and $\mathrm{n}$ is the number of samples discussed.

The years with more than $75 \%$ precipitation frequency are dry, and those with less than $25 \%$ precipitation frequency are wet. The precipitation level of corresponding years is the empirical precipitation value.

\subsubsection{Precipitation concentration degree and concentration period}

Precipitation concentration degree (PCD) and concentration period (PCP) are parameters defining regional precipitation time distribution characteristics based on the principle of vector analysis [21], wherein PCD can reflect the concentration degree of precipitation in the research period, and PCP can reflect the period of maximum precipitation in a year. The specific formula is as follows:

$$
\begin{gathered}
\left\{\begin{array}{r}
P C D=\frac{\sqrt{R_{x i}^{2}+R_{y i}^{2}}}{R_{i}} \\
P C P=\arctan \left(\frac{R_{x i}}{R_{y i}}\right)
\end{array}\right. \\
\left\{\begin{aligned}
R_{x i} & =\sum_{j=1}^{n} r_{i j} \times \sin \theta_{j}
\end{aligned}\right. \\
R_{y i}=\sum_{j=1}^{n} r_{i j} \times \cos \theta_{j}
\end{gathered}
$$

$R_{i}$ is the total precipitation in the first year during the research period of a certain station; $r_{i j}$ is the precipitation on the 10th day of the first year in the study period. $\theta_{j}$ is the azimuth corresponding to $j$ days $\left(0 \sim 360^{\circ}\right)$ in the study period. $\mathrm{I}$ is the year $(i=1980,1981 \ldots 2020)$, and $\mathrm{j}$ is the chronological order of the research period. Formula (2) reflects the precipitation concentration degree of total precipitation in the study period, and the value is between $0.0 \sim 1.0$. The closer the PCD value is to 1.0 , the more precipitation is concentrated in a certain period. On the contrary, the closer the PCD value is to 0 , the more uniform precipitation is. Formula (3) calculates the azimuth of the resultant vector. It marks the Angle indicated by the center of gravity after the resultant vector, reflecting the period when the maximum precipitation occurs. To reflect the corresponding relationship between PCP and every ten days in the middle of the year more clearly, the median value of the corresponding azimuth Angle of each ten days is selected (for example, the value of the first ten days of January is 0 to $10^{\circ}$, and $5^{\circ}$ is selected as the corresponding Angle).

\subsubsection{Comprehensive index of short-time heavy precipitation disaster}

According to Classification of Meteorological Disasters of Short Duration Heavy Rainfall, the comprehensive index of short-term heavy rainfall disaster, is divided into four grades [21], which are the most serious $I_{\text {hra }} \geq 1.0$ (level 1), the serious $0.6 \leq I_{\text {hra }}<1.0$ Severe (level 2), More severe $0.4 \leq I_{h r a}<0.6$ (level 3) and General $I_{\text {hra }}<0.4$ (level 4). The calculation formula of $I_{\text {hra }}$ is:

$I_{\text {hra }}=I_{\text {pre }} \times 0.5+I_{\text {pin }} \times 0.3+I_{\text {cov }} \times 0.2$

$I_{\text {pre }}$ is the average precipitation index; $I_{\text {pin }}$ is the extreme index of precipitation intensity. $I_{c o v}$ is the coverage indicator.

\subsection{Research Methods}

Based on determining the standard of short-time heavy precipitation, the concentration degree and concentration period of short-time heavy precipitation in the Nantong area in 1980 to 2020 are counted. The time series of short-time heavy precipitation is constructed. Then, the linear trend analysis method was used to analyze the time series of each station [22].

The Mann-Kendall trend test was applied to the statistical precipitation concentration degree and concentration period series. The time series data with statistical variable $\mathrm{Z}$ greater than 0 showed an increasing trend. In contrast, the time series data with statistical variable $Z$ less than 0 showed a decreasing trend. When the absolute value of $\mathrm{Z}$ is greater than or equal to 1.28 , 1.64 and 2.32, it means that the changing trend of the data passes the significance test with a confidence degree of 
$90 \%, 95 \%$, and $99 \%$, respectively [23].

Morlet wavelet analysis is a time-frequency domain analysis method, which can analyze the local characteristics of periodic changes of time series, to see the changes of each cycle with time more clearly [24].

\section{RESULTS AND ANALYSIS}

\subsection{Annual Precipitation}

Through the analysis of annual precipitation data of stations in the Nantong area from 1980 to 2020, it is found that the average annual precipitation is between 1060.7 to $1156.6 \mathrm{~mm}$, and the peak annual precipitation of stations generally occurs in flood season (May to September), among which the late June to early July is the plum rain season. The total precipitation during this period accounts for about $22 \%$ of the total annual precipitation.
The statistics of precipitation frequency show that the spatial distribution of precipitation is not uniform at all stations in Nantong. After averaging the empirical precipitation values of precipitation in good years and dry years at all stations in Nantong, the difference between the empirical precipitation values and the mean value is calculated. The anomaly values of precipitation in good years and dry years are calculated all stations are obtained. Fig. 2 has analyzed the anomalies of harvest and precipitation in dry years precipitation stations listed, from the point of rainfall harvest anomaly, Nantong central and southern regions (Nantong, Hangzhou, qigong, chairman) value is greater than zero, from the point of precipitation anomaly dry years, Nantong central region, some, Lv Si, Hangzhou, Nantong, chairman) anomaly value greater than 0 , thus it can be seen that the spatial distribution of precipitation in Nantong is larger than in other coastal and inland areas.

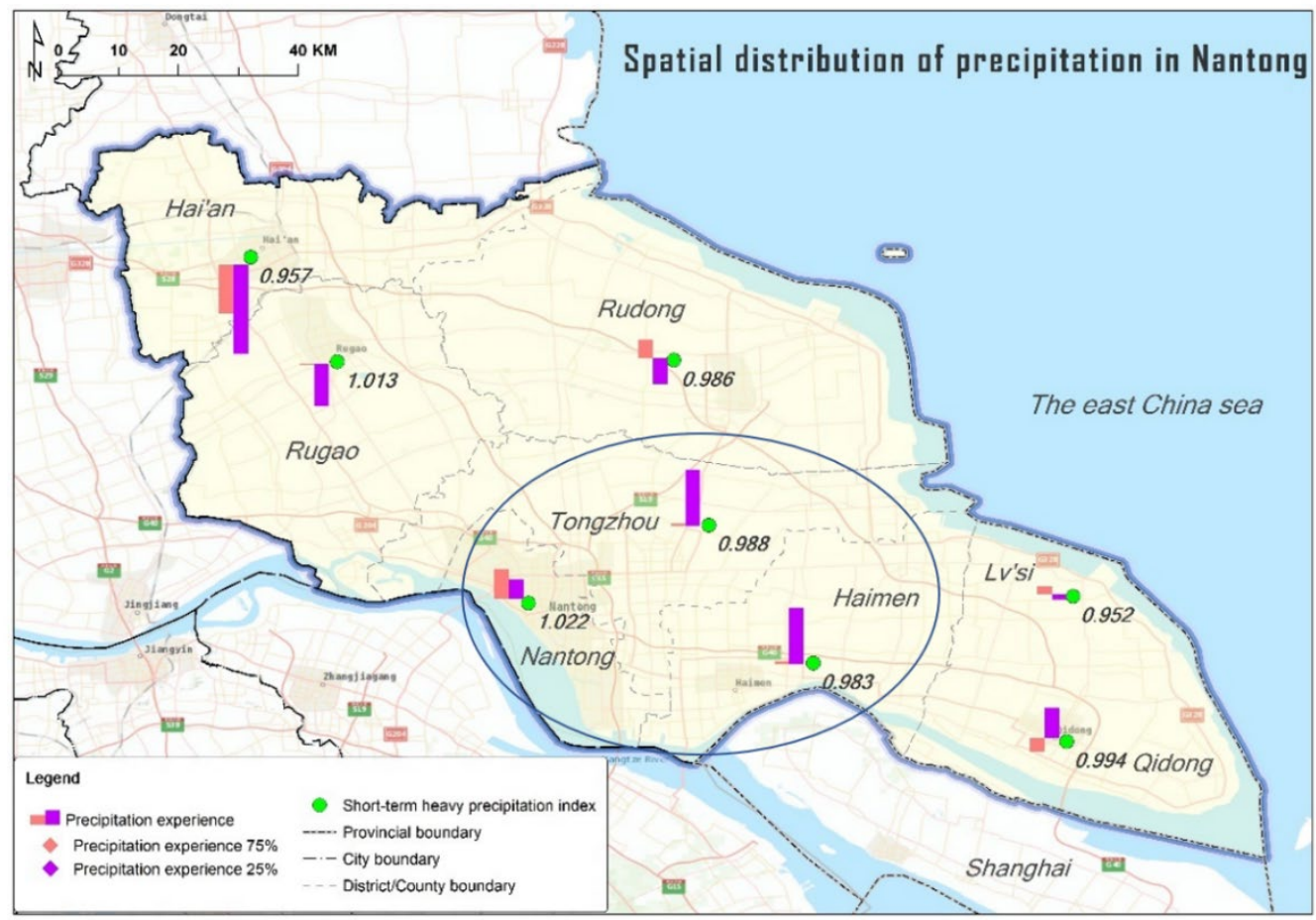

Figure 1. Empirical frequency distribution of annual precipitation at each station in Nantong.

Morlet wavelet analysis of the annual precipitation of each station in Nantong shows that the main cycle of each station is 32 to 33 years, and the second cycle is 7 to 8 years. Considering that the sample years are 41 years, the second cycle is considered credible for further discussion. Fig. 1 shows the Morlet wavelet analysis results of the average annual precipitation at each station in Nantong. It can be seen from Fig. 1 that the average annual precipitation at each station shows an alternation of 8year cycles. From 1980 to 2020, there have been about 5 cycles of dry and abundant transitions. 1981-1988, 19982005 and 2013-2020 are relatively wet years. 1989-1997 and 2006-2012 were relatively dry years. From the point of view of signal intensity, the signal intensity in 19841986, 1999-2003 and 2014-2018 were the strongest in the rich years, and the signal intensity in 1992-1994 and 2007-2012 was the strongest in the dry years. Nantong stations' actual annual precipitation anomalies were significantly higher in 1985, 1987, 1999-2001, 20142016 and 2020, and significantly lower in 1992-1996, 2003-2005 and 2011-2013. It can be seen that this cycle has a high degree of agreement with the actual precipitation cycle, which can be used as a reference for the prediction of precipitation transition between rich and dry years. 


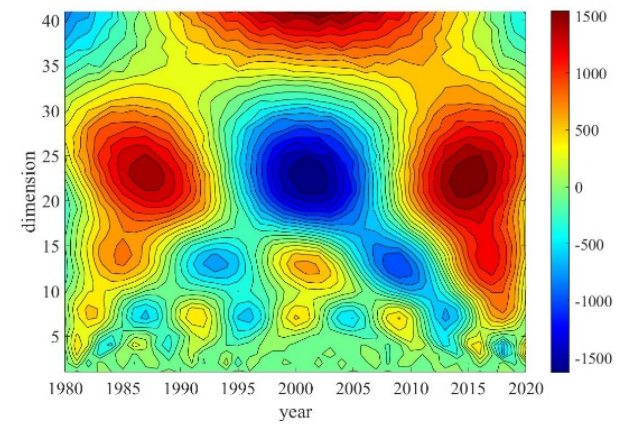

Figure 2. Morlet wavelet analysis results of average annual precipitation at various stations in Nantong

It is found that the years with significantly more or less precipitation in the plum rain period should also have significantly more or less annual precipitation. Conversely, the years with significantly more or less annual precipitation may not necessarily significantly have more or less precipitation in the plum rain period. In addition, the years with significantly more plum rain periods were all in the range of wet precipitation years (annual precipitation $>12666.6 \mathrm{~mm}$ ), and the years with significantly fewer plum rain periods were all in the range of dry precipitation years (annual precipitation < $946.6 \mathrm{~mm})$. The correlation analysis between plum rainfall and annual precipitation shows that the correlation coefficient is 0.5694 , indicating a certain correlation between them. According to the MannKendall trend test, the annual mean mei-rainfall increased $(\mathrm{z}=0.46)$, and the annual mean rainfall increased significantly $(\mathrm{z}=1.77)$.

According to the spatial distribution of Fig. 2, the comprehensive index values of short-time heavy precipitation disasters in inland areas of Nantong (Nantong and Rugao) are 1.022 and 1.013, respectively, which are larger than those of other stations along the river and coastal lines (0.952-0.994). That is, the grade of short-term heavy rainfall meteorological disaster in inland areas of Nantong is Level 1 (most serious), and the grade of other stations is level 2 (serious). Furthermore, the correlation between the annual precipitation disaster index and annual precipitation was analyzed, and the correlation coefficient was 0.7211 , indicating that there was an obvious linear correlation between them.

Combining the above analysis, Nantong central inland annual rainfall is more than the rest of the site, short-time strong rainfall meteorological disaster grade higher than the rest of the site, the flood control and flood control and waterlogging prevention of urban management difficulty and the demand of network optimization is more urgent than the rest of the site, the causes of the above results may be due to Nantong city in central China on the one hand, economic and social development is rapid, The intensity of human activities is generally higher than that of other stations, resulting in a significant increase in precipitation extremes 18]. On the other hand, this is due to the interaction between the hydrological cycle and mesoscale land-sea coupling mechanism, which is caused by riverfront topography in the Nantong area [25].

\subsection{Temporal changes of short-time heavy precipitation}

According to the statistics of the cumulative occurrences of $20 \mathrm{~mm} / \mathrm{h}$ short-time heavy precipitation from 1980 to 2020, the average occurrences of each station are 179.5 times, and the exceeding average occurrences are 232 times in Nantong, 192 times in Tongzhou, and 184 times in Hai 'an. The years with more short-time heavy precipitation also have more annual precipitation, and the year is in the precipitation bumper year area. According to the Mann-Kendall trend test, it is found that the annual average number of short-time heavy rainfall has a significant increase trend $(\mathrm{z}=1.74)$, which is consistent with the trend of annual average rainfall and annual average rainfall in the plum rain period analyzed above. The monthly distribution of short-time heavy precipitation at all stations in Nantong was analyzed (Fig. 3). It was found that the precipitation was relatively concentrated from late June to midSeptember. The short-time heavy rainfall appeared in early March at the earliest and in mid-November at the latest, with the highest frequency in late June, early August and late August. In summary, it can be seen that short-term heavy precipitation and other extreme precipitation events in summer are frequent and have an increasing trend, confirming that the summer extreme precipitation events with abundant precipitation have the best correlation with the total precipitation [26].

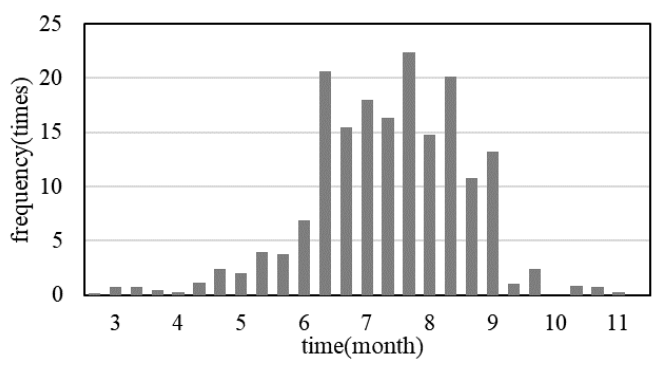

Figure 3. Monthly variation of mean frequency of short-time heavy precipitation

In late June, the short-time heavy rainfall in Nantong is closely related to the summer monsoon and subtropical high and coincides with the plum rain period in Nantong. In early and late August, short-time heavy rainfall is closely related to tropical weather systems such as subtropical highs, typhoons, and easterly storms [17]. Because southeast wind prevails in Nantong in summer half year and northwest wind prevails in winter half year, from the perspective of spatial distribution, Nantong station is downwind of Tongzhou station in summer half year. The annual average temperature of Nantong station is higher than that of surrounding stations, which is an 
inland city, in line with urban heat island effect. Studies have shown that the result of the urbanization not only can make the rain island, also enhance the level of urban wind speed and wind direction area under water conveying, and strengthen the convergence and upward movement, downwind area precipitation increase in downwind region [27-30], therefore, nantong site shorttime strong rainfall in most times a certain extent, can be summed up in the cause of urban heat island effect.

By analyzing the diurnal variation of short-time heavy precipitation at all stations in Nantong (Fig. 4), it is found that short-time heavy precipitation tends to occur frequently in the morning (4-7 o'clock) and from the afternoon to the early night (13-19 o'clock), which conforms to the characteristics of double peak values in the Jianghuai River Basin [29], and the short-time heavy precipitation around midnight (23:00 to 3:00 O 'clock) is relatively low. Compared with Nantong, Tongzhou and Haian, the three stations with the highest frequency of short-time heavy precipitation, it is found that the shorttime heavy precipitation in Nantong is more concentrated at 16:00, 17:00 and 19:00. In Tongzhou, the distribution is more uniform in the morning and evening. Haian is more concentrated at $4 \mathrm{o}$ 'clock and $15 \mathrm{o}$ 'clock, which can explain to some extent that the diurnal variation of short-time heavy precipitation in different regions also has certain spatial differences. On the one hand, the reasons leading to the spatial differences in the diurnal variation of short-time heavy rainfall can be attributed to the local thermal circulation caused by terrain distribution, sea-land distribution, etc. On the other hand, they are also closely related to the large-scale circulation background, the movement of the large-scale convective system, and the airflow guided by the mesoscale convective system 17].

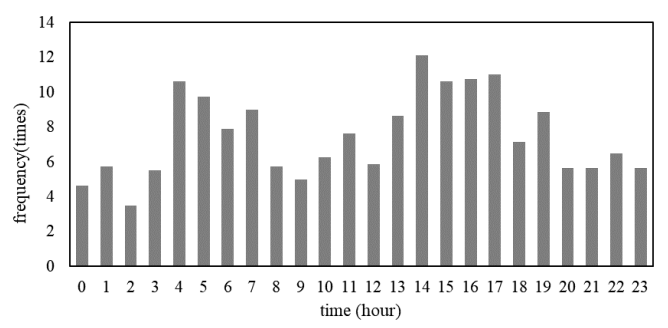

Figure 4. Diurnal variation of the average frequency of short-time heavy precipitation

\subsection{Precipitation concentration degree and concentration period of short-time heavy precipitation}

When analyzing the precipitation concentration degree of short-time heavy precipitation, The Times and accumulated rainfall of short-time heavy precipitation every ten days from 1980 to 2020 were firstly counted. According to the accumulated rainfall and accumulated rainfall of short-time heavy precipitation in a year, the average precipitation concentration degree of short-time heavy precipitation in each station was obtained. The average range of the value was 0.6-1.0, indicating a high precipitation concentration degree. In 1980 and 1986, the value was 1.0 , with the highest concentration, while in 1983, 1987 and 2018, the value was 0.6, with the lowest concentration. The corresponding Angle of the average precipitation concentration period of $20 \mathrm{~mm} / \mathrm{h}$ short-time heavy precipitation at each station is between $163^{\circ}$ and $233^{\circ}$, corresponding to the late June to the middle of August, which covers the plum rain period that occurs all year round in Nantong area.

The Mann-Kendall trend test was conducted on the precipitation concentration degree and concentration period data of short-time heavy precipitation. After passing the $90 \%$ significance test, the following conclusions were drawn: the concentration degree of short-time heavy precipitation events at all stations in Nantong weakened and tended to disperse to every ten days, and the short-time heavy precipitation concentration period at all stations in Nantong tended to move on later (except Hai 'an).

The correlation coefficient between the annual mean number of short-time heavy rainfall and precipitation in the plum rain period is 0.4156 . Between short-time heavy rainfall and annual mean precipitation is 0.5774 . The correlation coefficient between the annual mean precipitation and the annual mean precipitation in the plum rain period is 0.3395 , and the correlation coefficient between the annual mean precipitation is 0.4954 . Thus, the correlation coefficient between precipitation in the plum rain season and annual precipitation is 0.5694 . It indicates that the frequency of short-term heavy rainfall and the increase of precipitation will affect the increase of precipitation in the plum rain season and annual precipitation.

After Morlet wavelet analysis, it is found that the precipitation concentration period of short-time heavy precipitation is 5 years, the precipitation concentration period of short-time heavy precipitation is 8 years, the annual average frequency of short-time heavy precipitation is 8 years, and the annual average precipitation period of short-time heavy precipitation is 8-10 years. Thus, the precipitation concentration period, annual average number, and annual average precipitation cycle of short-time heavy precipitation are consistent with each station's annual cycle of abundant and dry average precipitation. The precipitation concentration cycle of short-time heavy precipitation is about 3 years behind. Therefore, it can be inferred that during the 14th Five-Year Plan period (2021-2025), the overall concentration degree of short-time heavy precipitation in Nantong tends to be scattered, and the concentration period tends to be delayed. The frequency and precipitation of short-time heavy precipitation will still be in the large range. 

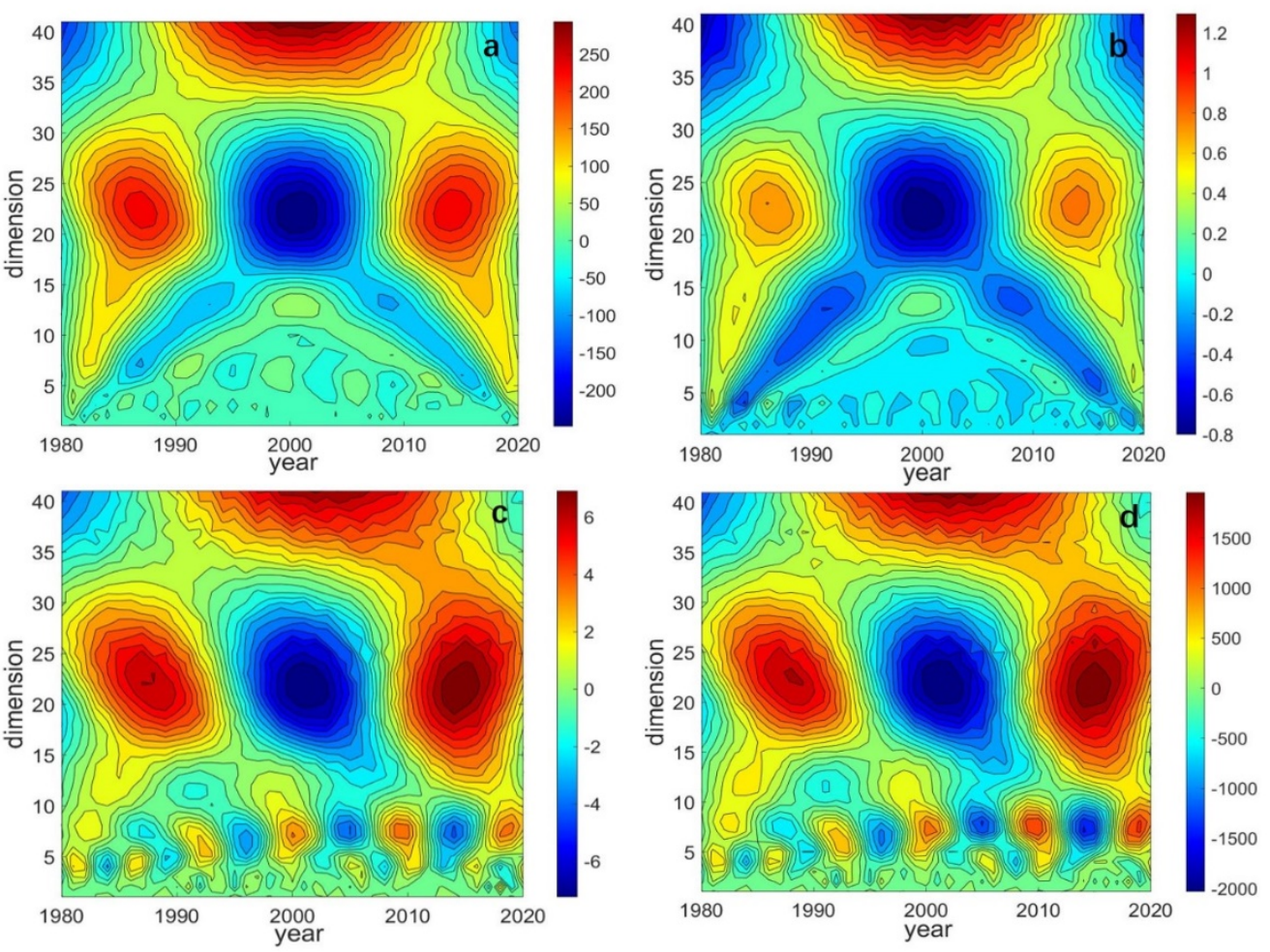

Figure 5. Morlet wavelet analysis of short-time heavy precipitation (a: precipitation concentration period of shorttime heavy precipitation, b: precipitation concentration degree of short-time heavy precipitation, c: annual average

number of short-time heavy precipitation, $\mathrm{d}$ : annual average precipitation of short-time heavy precipitation)

Urbanization will increase the short-term strong precipitation event frequency [31-33], is produced by the geographical advantage of Nantong region connects the Yangtze River and the sea dimension scale type economic growth in recent years, is now in the long triangle region of the country's international square, 14 or 15 planning is will speed up the construction of " Yangtze River Delta integration shanghai-Suzhou Link core triangle strong fulcrum city " as the target. In this context, high-level planning and construction of urban smart flood control and drainage facilities and standard sponge city, resilient city, ecological city and climate-resilient city construction needs will become one of the cornerstones to achieving the above overall planning objectives.

\section{Conclusion}

Based on the analysis of hourly, daily and yearly precipitation data in Nantong from 1980 to 2020, the conclusions are as follows:

There are central in the spatial distribution of precipitation in Nantong area (circle) is greater than the other characteristics of the coastal and inland areas, Nantong central inland annual rainfall is more than the rest of the site, short-time strong rainfall meteorological disaster grade higher than the rest of the site, the flood control and flood control and waterlogging prevention of city management difficulty and the demand of city pipe network optimization is more urgent than the rest of the site. The average annual precipitation at each station in the Nantong area shows an alternating cycle of 8 years, which has a high coincidence with the actual precipitation cycle, which can be used as a reference for predicting precipitation transition between abundant and dry years.

The short-time heavy precipitation at all stations in Nantong mostly occurred in flood season (From May to September). The diurnal variation was consistent with the characteristics of double peak values in The Yangtze River and Huaihe River Basin. The frequency of shorttime heavy precipitation in Nantong was the most frequent. The increase of short-time heavy precipitation and precipitation would affect the increase of precipitation in the plum rain season and annual precipitation. According to the periodic changes of precipitation concentration period, annual average frequency and annual average precipitation of short-time heavy precipitation, it can be inferred that the overall concentration degree of short-time heavy precipitation in the Nantong area tends to be scattered during the 14th Five-Year Plan period (2021-2025). The concentration period tends to be delayed, and the frequency and precipitation of short-time heavy precipitation will still be in the large range. Therefore, understanding the risk of waterlogging in the Nantong region, quantifying the benefit analysis of engineering measures to adapt to climate change, and realizing the fine management of waterlogging risk will become one of the primary topics to achieve high-quality development in the next stage. 


\section{REFERENCES}

[ 1 ] Wu Wenbo. You Qinglong. Wang DAI. Characteristics analysis of extreme precipitation in China based on homogenized precipitation data. Journal of Natural Resources,2016,31(6):10151026

[2 ] GDV. Forschungsprojekt Starkregen. Available online:

https://www.gdv.de/de/themen/news/forschungspro jekt-starkregen-52866 (accessed on 25 November 2019).

[3] LIU Z M, HU B Q, YAN Y, et al. Intra-annual in homogeneity characteristics of precipitation in Guangxi Beibu Gulf Economic Zone $[\mathrm{J}]$. Water Power, 2017, 43(6): 23-27.

[4] QIN W J.LI D L. A study on the climate change characteristics of all kinds of precipitation events in recent 50 years of Guangxi J ] . Journal of Natural Rsources, 2014, 29(4): 666-676.

[5] Konstantia Tolika. On the analysis of the temporal precipitation distribution over Greece using the Precipitation Concentration Index (PCI): annual, seasonal,monthly analysis and association with the atmospheric circulation. Theoretical and Applied Climatology. https://doi.org/10.1007/s00704-0182736-6

[ 6 ] Gerardo Núñez-González. Comparison of the behavior of the precipitation concentration index on global and local scale. Theoretical and Applied Climatology ,https://doi.org/10.1007/s00704-01902996-5

[7] Zhao Dongsheng, Gao Xuan, Wu Shaohong, et al. Trend of climate variation in China from 1960 to 2018 based on natural regionalization $[\mathrm{J}]$. Advances in Earth Science,2020,35(7):750-760. DOI : $10.11867 / \mathrm{j} .1$ ssn.1001-8166.2020.056.

[8] YANG S Y, LU Q F, JU X H, et al. The nonuniformity characteristic of extreme precipitation in Northeast China during the flood period during 1961 $-2010[\mathrm{~J}]$. Transactions of Atmospheric Sciences, 2011, 34(6):756-762.

[ 9 ] YANG W, HE J H, WANG P X, et al. Inhomogeneity characteristics of intra - annual precipitation over the Tibetan Plateau in recent 42 years $[\mathrm{J}]$. Journal of Geographical Sciences, 2011,66(3):376-384.

[10] QIN W J, LI D L, LEI X M, et al. Analysis on inner - annual inhomogeneity of rainstorm events in Guangxi $[\mathrm{J}]$. Journal of Tropical Meteorology, 2012, 28(2): 258-264.
[11] Yuan Ruiqiang. Wang Yanan. Wang P, et al. Variation characteristics and influencing factors of precipitation concentration: A case study of Shanxi Province [J]. Advances in climate change research,2018,14(1): 11-20

[12] MAO Dongyan. Cao Yancha. Zhu W J, et al. Analysis on climatic characteristics of short-time heavy rainfall in Southwest China [J], Meteorological Monthly,2018,44(8):1042-1050

[13] Boers, N., Goswami, B., Rheinwalt, A., Bookhagen, B., Hoskins, B.and Kurths, J. (2019) Complex networks reveal global pattern of extreme-rainfall teleconnections. Nature, 566, 373377.https://10.1038/s41586-018-0872-X

[14] Richard P. Allan. Stephen Blenkinsop. Hayley J. Fowler. Atmospheric precursors for intense summer rainfall over the United Kingdom. International Journal of Climatology. 2020(1)6:3849-3867

[15] Tsubasa Hashimoto et. Countermeasure against Increase of Heavy Rainfall. Journal of Water and Environment Technology,Vol.12, No.2,2014

[16] D. Ceresetti et. Scaling properties of heavy rainfall at short duration :A regional analysis. WATER RESOURCES RESEARCH, VOL. 46, W09531, doi:10.1029/2009WR008603, 2010

[17] Jiong Chen. Yongguang Zheng. Xiaoling Zhang. Distribution and diurnal variation of short-time heavy rainfall in warm season and its relationship with mesoscale convective system in China. Journal of meteorological, 2013.71(3):367-382

[18] Huang Jie. Gao Lu. Chen Xingwei. Chen Y, et al., Variation characteristics and attribution analysis of precipitation extremes in the first flood Season in southeast China. Journal of geographical,2016,71(1):153-165

[19] Implementation opinions of The General Office of the State Council on strengthening the control of Urban waterlogging. State Affairs and Development (2021) No.11.

[20] Classification of meteorological disasters with short duration heavy rainfall, DB 14/ T 1986-2020

[21] Cao Yongqiang. Lu Lu. Zhang Tingting. Spatial and temporal variation characteristics of precipitation in Zhejiang Province based on precipitation concentration degree and concentration period. Resources science,2013,35(5):1001-1006

[22] Wu Wenbo, You Qinglong, Wang Dai. Analysis of extreme precipitation characteristics in China based on homogenized precipitation data $[\mathrm{J}]$. Journal of Natural Resources. 2016, 31(6): 1015-1026. 
[23] Bai Shuying. Gu Haimin. Shi J Q. Et al. Spatiotemporal variation of rainstorm days in the Yangtze River Basin in recent 50 years [J]. Resources and Environment in the Yangtze River Basin.2015, 24(7): 1255-1262.

[24] Han Zhiming. Jaceli. Yang F, et al. Multi-time scale analysis of precipitation in Hulun Lake Basin based on Morlet wavelet. Research on Soil and Water Conservation.25(1): 160-166

[25] Ren Guoyu, Zhan Yunjian, Ren Yuyu, et al. Spatialtemporal variability of precipitation in Mainland China -- I. Climatological characteristics, advances in water science,2015,26(3):299-310, DOI: 10. 14042/j. cnki. 32. 1309. 2015. 03. 001

[26] Yang W. Cheng Z. Variation characteristics of extreme precipitation in Meiyu period of Jianghuai River Basin in recent 53 years. Meteorological, 2015,41(9):1126-1133

[27] Palumbo A, Mazzarella A. Rainfall statistical properties in naples $[\mathrm{J}]$. Mon Wea Rev, 1980, 108(11): $1011-1015$.

[ 28 ] INAMURA T.IZUMI T.MATSUYAMA H. Diagnostic study of the effects of a large city on heavy rainfall as revealed by an ensem-ble simulation: a case study of central Tokyo.Japan [J] . Journal of Applied Meteorology and Climatology,2011,50(3): 713-728.

[29] Zhu LI. Miao Junfeng. Research progress of urban Heat island Circulation in China, Meteorological Science and Technology, 2019,47(1):52-61

[30] Hu Qingfang. Zhang Jianyun. Wang Yantang et al. Review of studies on the impact of Urbanization on precipitation, Advances in water science, 2018,29(1):139-150

[31] ZHENG Y P, LI J L, ZHAO S Q, et al . Urbanization impact on precipitation of Urumqi city in recent $48 \mathrm{a}[\mathrm{J}]$. Arid Land Geogra-phy,2011,34( 3):442-448.

[32] SONG X M, ZHANG J Y, KONG F Z, et al. Spatio-temporal variation characteristics of precipitation extremes in Beijing $[\mathrm{J}]$. Advances in Wa-ter Science, 2017, 28( 2) : 161-173.

[33] JIN Y R, HU Q F, WANG Y T, et al. Impacts of rapid urbanization on precipitation at two representative rain gauges in Shanghai City [J] . Journal of Hohai University ( Natural Sciences),2017,45( 3): 204-210. 